\title{
Luke Golemon
}

\author{
Medical Overtesting and Racial Distrust
}

\begin{abstract}
The phenomenon of medical overtesting in general, and specifically in the emergency room, is well known and regarded as harmful to both the patient and the healthcare system. Although the implications of this problem raise myriad ethical concerns, this paper explores the extent to which overtesting might mitigate race-based health inequalities. Given that medical malpractice and error greatly increase when the patients belong to a racial minority, it is no surprise that the mortality rate similarly increases in proportion to white patients. For these populations, an environment that emphasizes medical overtesting may well be the desirable medical environment until care evens out among races and ethnicities; additionally, efforts to lower overtesting in conjunction with a high rate of racist medical mythology may cause harm by lower testing when it is actually warranted. Furthermore, medical overtesting may help to assuage racial distrust. This paper ultimately concludes that an environment of medical overtesting may be less pernicious than the alternative.
\end{abstract}

\section{MEDICAL OVERTESTING}

The phenomenon of medical overuse in general and specifically medical overtesting is well known and harmful to both the patient and the healthcare system (Boland, Wollan, and Silverstein 1996; Shapiro and Greenfield 1987; Bishop, Federman, and Keyhani 2010; Greenberg and Green 2014; Morgan et al. 2015). It is estimated that between 10\% and 30\% of all care is overuse, depending on the definition and method (Berwick and Hackbarth 2012; Morgan et al. 2015; Smith 1991). Overtesting is just one kind of overuse, but a kind I argue is different from its siblings. Unlike other forms of overuse, it is not obvious we should focus significant effort into reducing it. Because minority groups (specifically black Americans) are liable to be victims of medical underuse and physicians' perceptions of underuse and overuse in individual cases can be affected by unconscious bias, these groups do not suffer the harms of overtesting in the same way as others. Furthermore, race-neutral policies aimed at reducing undertesting might further lower treatment minority groups already receive, increasing already-existent health inequities. Finally, if we are to reduce it via some policy, we should strongly consider race- 
conscious policies. ${ }^{1}$ Before I can argue either point, more must be said about overuse and overtesting.

\section{The Nature of Overuse and Overtesting}

The reasons overuse occurs are hard to parse. According to some studies, defensive medicine plays some role in this - doctors feel pressure to do more than necessary to avoid liability, including testing (Greenberg and Green 2014; Mello, et al. 2010; Bishop, Federman, and Keyhani 2010). Other and more recent studies indicate that low-value care (some of which includes preventative care, such as medical tests) is driven primarily by local practices, patient expectations, or is idiosyncratic to certain diagnoses (Reid, Rabideau, and Sood 2016; Morgan et al. 2018). Medical overuse increases the cost of healthcare, puts patients' health at risk, and reduces the amount of time available with medical professionals for everyone (Greenberg and Green 2014; Mello, et al. 2010; Thomasian 2014). This gives us strong reasons to try to reduce medical overuse, of which overtesting is a part. Although awareness of medical overuse has greatly increased, practice remains largely unaffected (Morgan et al. 2015; Morgan et al. 2018).

Part of the issue is located in the definitions and concepts used to probe the problem. Overuse and underuse in a medical setting are typically thought of as paradigm cases of medical error. Medical error is conceptually broad. The Institute of Medicine report on medical error defines it as "[f]ailure of a planned action to be completed as intended or use of a wrong plan to achieve an aim" (Kohn, Corrigan, and Donaldson 2000, 210). It can be usefully thought of as the result of a knowledge-based or practice-based mistake in a medical setting. ${ }^{2}$ As Morgan et al.

\footnotetext{
${ }^{1}$ For more on policies that avoid my arguments or address my concerns, see the final section of the paper.

${ }^{2}$ For more on medical error, see Allhoff and Borden (forthcoming); Makary and Daniel (2016); and Kohn, Corrigan, and Donaldson (2000). Medical racism, both conscious and unconscious, causes much harm to minority
} 
point out, there are multiple overlapping concepts used to describe medical overuse:

overutilization, overmedicalization, low-value care, and so on (2015). ${ }^{3}$ Additionally, there are related concepts like overdiagnosis, overtreatment, and overtesting that are commonly used (Morgan et al. 2015). Many have adopted the Institute of Medicine's definition of medical overuse as "care in the absence of a clear medical basis for use or when the benefit of therapy does not outweigh the risk" (Institute of Medicine 2001). While I intend to focus on overtesting shortly, we should first critically examine this definition.

The primary issue with the definition is that it does not distinguish between two different readings: one is read as subjective while the other reading is objective. Suppose a physician examines a patient and their perception of the patient identifies symptoms that point toward a heart attack. The physician now has a medical basis for care. Suppose also that one of the symptoms that the medical field identifies as a symptom for heart attacks does not actually correlate with heart attack rates, although the medical community is unaware of this. Finally, suppose that the care involves managing this same problematic symptom. Now we have a case in which the physician believes they have a medical basis for care, but, objectively speaking, the benefit of therapy does not outweigh the risk. Under the definition above, this seems as if it is both a case of overuse and not a case of overuse.

To understand how to resolve this issue, we can draw an analogy to justified beliefs and true beliefs. It is commonly accepted among epistemologists that someone may be justified in holding a false belief. For example, someone might be justified in believing that they saw a zebra when they in fact only saw a cleverly disguised donkey (Alspector-Kelly 2019), or believing

communities. Recently, medical error due to racial bias has been emphasized (Schulman et al. 1999; Hoberman 2012; Staton et al. 2007).

${ }^{3}$ See also Carter et al. (2015). 
"laudable pus" to be healing (Nuland 2011). If "medical basis" is anything like justified belief, then it is possible to have a medical basis despite the therapy's actual costs and benefits being net negative.

It is likely that the definition of medical overuse is consistent, treating both concepts as subjective, ${ }^{4}$ but it is important to show that we rely on this subjective reading whether or not the Institute of Medicine conflated the issues. When determining how to reduce overuse, vacillating between readings may seriously hamper efforts. A brief foreshadowing is illustrative: bias can cause one person to perceive a situation in a different way than another; if there is no medical basis for care given a racially-biased evaluation, then the physician could believe they are entirely justified in withholding care when they in fact should provide it. While an objective reading of "medical basis" might help us find low-value care elsewhere, it seems to systematically overlook catching instances of subjective bias when evaluating whether something is low-value care by the physician.

This discussion generalizes to overuse's drivers. Overtesting specifically seems to have similar conceptual joints: physicians may overtest despite their perception that it is not necessary, or the community may learn that the benefits of a test do not outweigh the cost and fail to keep its members testing with best practices. The upshot is that we now can identify roughly two ways overtesting might be identified: one in which a physician accurately identifies a case in which "[testing] in the absence of a clear medical basis for use or when the benefit of therapy does not

\footnotetext{
${ }^{4}$ It can also be made consistent by reading both concepts as objective, but this leaves us without much epistemic access to cases of overuse and medical bases. For instance, if it is in fact the case that calcium and vitamin D supplements do not work as well as expected, then all such treatments to count as overuse, despite the medical community's ignorance. This is not intuitive. Instead, we seem to be pursuing the idea that there is some gap between knowledge and practice that should be closed. This gap can present at a personal and community level: a physician might know calcium supplements do not work well and yet still prescribe them or there might be findings of this nature and yet the community has not taken steps to ensure all its members follow best known practices. There are further issues, like how we would begin to know the extent of overuse, since it depends on having perfect knowledge.
} 
outweigh the risk", and one in which a physician believes they have identified such a case, but are incorrect for reasons including unconscious bias. Both of these are likely phenomenologically indistinguishable to the physician at the time. ${ }^{5}$

As with overuse, medical overtesting is regarded as harmful to the patient and the healthcare system. On this basis, there has been a push to rather bluntly reduce medical overtesting (Hendee et al. 2010; Morgan et al. 2015; Morgan et al. 2016). Once we learn that we use imaging tests much more often than necessary, physicians are encouraged to cut back on the use of such tests (such as the MRI or the CT scan). This is in addition to major systemic changes to liability and other non-legal financial incentives (Hendee et al. 2010). Moreover, the community-wide push to reduce medical overuse and waste likely seeps into individual practice. ${ }^{6}$ Notably, many of these anti-overtesting policies are race-neutral, which often contributes to their blunt nature with regard to problems of racial disparities. Below, I argue that we have assumed too quickly; the basis on which we have made the leap from overtesting to its reduction does not have a strong foundation. Characterizing harm in such a broad way neglects an important factor: racial minorities are not harmed by overtesting in the same way as other groups. $^{7}$ To see this more clearly, we should review some major points about medical racism.

\section{Black Experience and Medical Racism}

\footnotetext{
${ }^{5}$ More will be said on this topic in the titular section of the paper. I thank an anonymous reviewer and the editors of this journal for pushing me to clarify this.

${ }^{6}$ This is incredibly hard to find recent data on. Computed tomography scan usage certainly rose into 2007 , but the rates are unclear afterwards (Larson et al. 2011). Recent studies are piecemeal and often department specific, but it appears that usage has leveled off or decreased recently (Niles et al. 2017). Regardless, the goals of anti-overtesting policies are to affect individual practice in some way, so presumably this can be assumed.

${ }^{7}$ In what follows, I will focus largely on black Americans. It is important to acknowledge that minority experience can vary widely based on appearance, culture, and ethnicity, and so some of what is true about medical racism for black Americans will not be true for other minority groups. I do not have the space to defend each generalization from black American experience to other minority groups, so the reader is justified in rejecting any such generalizations. I am confident that if the argument is successful for black Americans, then generalizing to other minorities will only be a reason a forteriori.
} 
It is beneficial to begin with the facts of racial disparities and center the discussion at the margins before considering policies (Airhihenbuwa and Liburd 2006). The history of the United States is plagued with racism. Not only has intentional, interpersonal racism led to horrific acts, racial animus has created structures of power and attitudes that affect its victims in ways that may no longer involve interpersonal racists at all (Bonilla-Silva 2017). Hardly any aspect of society has been left untouched. ${ }^{8}$ Medicine has fared no better. For more than a thousand years, black biology and black intellectual ability have been denigrated or assumed to be inferior. ${ }^{9}$ From Galen to Avicenna to Carl Linnaeus, the luminaries and founders of medicine have diagnosed darker-skinned peoples with primitivity, savagery, stupidity, or categorized them as wholly subhuman (McBride 2018; Byrd and Clayton 2001). As each new scientific theory was developed, racism was either already present or quickly twisted the theory to support itself. For example, it was not long before Darwinian physicians and natural scientists proclaimed that they had found the missing link between apes and humans: black people (Drake 1987, Byrd and Clayton 2000).

This inevitably led to healthcare that was entirely inadequate and often pernicious. A lexicon of "Negro diseases" was developed (Byrd and Clayton 2001). Almshouses, medical centers for the "undeserving poor" were built to house black patients (Rosenberg 1987). Hospitals denied service to any but whites or would abuse black patients (Rosenberg 1987). It goes without saying that medical training was an exclusively white privilege.

\footnotetext{
${ }^{8}$ For more on how health inequities are an extension of racial power dynamics to this day, see Airhihenbuwa and Liburd (2006).

${ }^{9}$ See Byrd and Clayton (2000; 2001), Montagu (1963), Lewis (1990), and Drake (1990).
} 
The Tuskegee experiment is illustrative of these attitudes within the medical field. In the government-approved and government-funded study, 622 poor black men were monitored to study the progression of syphilis. Despite developing an effective cure during the study, the men did not receive any such treatment. Furthermore, none of the men was informed of his illness or of the true timeline of the study. None of the men was ever given penicillin, an effective cure for the disease, during the experiment. This study was not halted until 1972, only after its horrors were leaked to the press.

This racist history has not merely influenced the present day-it is continuous with it. As Vanessa Gamble put it, "the problem we must face is not just the shadow of Tuskegee but the shadow of racism that so profoundly affects the lives and beliefs of all people in this country" (Gamble 1997). Many accept that there was racism, even medical racism, up to the 1920s (Hoberman 2012; Byrd and Clayton 2001; Smedley, Nelson, and Stith 2003). The Tuskegee experiment is emblematic of the continuing racism up till its halt in 1972. But this was not the end:

More than 600 studies have documented racial and ethnic differences in health care dating back at least to the 1980s. These studies suggested that racial and ethnic differences reflect, in part, underuse by black patients who fail to receive these procedures when their use is clinically appropriate. (Jha et al. 2005, 690; Hoberman 2012, 235)

In 1999, Schulman et al. found that black patients were less likely to be referred for cardiac catheterization than white patients, and black women less than white men, white women, or black men. This revelation sent shockwaves through the medical community, but anyone familiar with the data or the history of medical racism was not surprised (Byrd and Clayton 2001). It is not that we are shaking off the remnants of racism from the Civil War, or the Civil Rights movement, or anything of the sort (McBride 2018). We are actively - although perhaps 
unconsciously - engaged in the same, continuous, pejorative, and centuries-long history that has so badly wronged black people in America.

Modern medical racism may be less intentional, but it still exists in both interpersonal and structural forms (Hoberman 2012; Gee and Ford 2011; Massey and Sampson 2009). While intentional, interpersonal racism is evil, structural racism and unconscious biases lead to true medical error, which perhaps entails less blame. I will quickly survey some ways these racial divides occur and why doctors propagate them, even if unintentionally, through two fruitful examples. First, physicians refer black patients for cardiac catheterizations less often than their white counterparts (Centers for Disease Control and Prevention [CDC] 2017). Second, black women have incredibly high maternal mortality rates in comparison to white women (CDC 2017). These examples are not just paradigm instances of medical racism, but illuminative examples, as we will see.

In a well-publicized study, Schulman et al. showed unequivocally that clinical outcomes are affected by race (1999). ${ }^{10}$ Physicians are significantly less likely to refer a patient for cardiac catheterizations if the patient is black, and even less likely to do so if the patient is a black woman. Although the study leaves open why the physicians did so, John Hoberman details how this sort of medical malpractice can come about. Medical "gossip," still thrives in the medical field simply by filtering patients and experiences with them through the doctor's personal beliefs (Hoberman 2012, 12-13). ${ }^{11}$ Unfortunately, doctors' personal beliefs do not vary much from the public when it comes to racial attitudes. Just like the public, "whites have largely abandoned

\footnotetext{
10 They also showed it is affected by gender, but I will focus on race here. One point to be made, however, is the effect of intersectionality is clearly evident. Being both black and female is worse than being only black or only female in terms of clinical treatment and outcome.

${ }^{11}$ These biases also can be passed down via the elder attending physicians and precepting. Certain forms of training, infrastructure changes, feedback, and education might correct for this.
} 
principled racism ${ }^{12}[\ldots$ but $]$ they have not necessarily given up negative racial stereotypes" or other negative attitudes about people of color (Hoberman 2012, 12-13; Massey and Sampson 2009).

This has been further corroborated by studies about pain treatment. It has been welldocumented that black patients' pain is both underestimated and undertreated by the medical community, even in cases involving children (Smedley, Nelson, and Stith 2013; Anderson, et al. 2009; Cintron and Morrison 2006; Freeman and Payne 2000). The causes of this might be a number of factors, but one of the best explanations is the actual content of medical professionals' beliefs about different races. Many of the researchers studying the phenomenon argue that doctors simply assume that black patients experience less pain than white patients. Consider a study by Staton et al.: patients were asked to report how much pain they were currently experiencing, and doctors were to report how much pain they thought the patients were experiencing. The mismatch was quite large: black patients' pain was significantly underestimated compared to non-black patients (47\% to 33.5\%) (2007).

This fits with other findings adjacent to this point. Many people simply believe biological falsities about black bodies, and medical professionals are no exception. Many believe black people are biologically more athletic as a result of natural selection or even from breeding during slavery (Hoberman 1997; Morning 2011). In a study in 2016, white medical students and residents were found to hold biologically false beliefs about the black body. In this case, their beliefs centered on pain tolerance (Hoffman, et al. 2016). ${ }^{13}$ The focus was not just to see if there

\footnotetext{
${ }^{12}$ Principled racism is the explicit belief that one race is better than another. Contrast this with harboring negative racial stereotypes, which can coexist with genuine affirmations of racial equality.

${ }^{13}$ This might have relevant disanalogies. One is about susceptibility, the other about exceptionalism. Furthermore, claims about black athletes are demonstrable, whereas claims about pain require trust in the reporter. The analogy here is not necessarily affected by these differences - instead, I wish to draw attention to the willingness to believe falsities about black bodies in general, even in the face of evidence (reported or demonstrable).
} 
were widespread false beliefs, but if they led to different treatment recommendations in which the symptoms of black patients were downplayed - which they did. Although these beliefs do not necessarily constitute racism, they can and do have impacts on how black people are treated and correlate with acceptance of racial disparities and outcomes as unproblematic (Williams and Eberhardt 2008). ${ }^{14}$

Given the data cited above, it seems that we have a fairly straightforward explanation for why treatment and recommendations might differ between white and black patients: physicians falsely believe that black patients simply aren't experiencing what they profess to be experiencing. ${ }^{15}$ If patients are experiencing severe chest pain, this is a reason to refer them for heart treatment. If the physician believes patients are only experiencing mild pain, then there is much less reason for the referral. Physicians systematically underestimate the pain of black patients; therefore, it should be no surprise that black patients often receive less treatment when pain is a significant symptom. Of course, there are other explanations along this line. Consider that, for a long time, doctors did not think that African-Americans could develop myocardial infarction (a certain kind of heart disease), or that they believe black people have fewer nerve endings, or any number of other false biological beliefs that many medical professionals hold (Hoffman, et al. 2016; Hoberman 2012). ${ }^{16}$ What is important is that a significant amount of

\footnotetext{
${ }^{14}$ Some have indicated that this might be due to race being treated as entirely biological in the medical literature, or nearly so. See Doll, Snyder, and Ford (2018).

${ }^{15}$ These are not the only factors that affect health outcome inequities. Social disadvantage, class stratification, high healthcare needs without corresponding availability of care, systemic racism in other sectors (e.g., environmental racism of dumping pollutants and trash), and so on all have major impacts on health inequities. For more discussion on these and other possible drivers of health inequities, see King (2007). For more on racial segregation as a fundamental source of racial disparities in health, see Williams and Collins (2001). For more on how power plays a role in most of these inequities, see Airhihenbuwa and Liburd (2006).

${ }^{16}$ Some of these other beliefs include thicker skin and blood that coagulates more quickly, for instance. The point is less that any one of these explanations explains the phenomena, but that whatever explanation succeeds, it will be one that includes false biological beliefs. Alternatives to these false biological belief systems are largely unsupported (e.g., that medical personnel are consistently interpersonally racist about these matters and prescribing too few pain medications to black patients out of malice).
} 
undertreatment is almost certainly due to biological beliefs that, unbeknownst to the physicians and other medical personnel who hold them, are false.

W. E. B. DuBois was one of the first to study the white/black disparity in infant mortality rates sociologically, and from which racial injustice is easily inferred (1899). At the time, the black infant mortality rate was $340 / 1000$ births whereas the white infant mortality rate was 217/1000 births. Although both have decreased significantly, the disparity between black and white infant mortality rates has remained steadfast. Today, a black baby is more than twice as likely to die than a white baby-11.3/1000 compared to $4.9 / 1000$, a statistic that has recently received media attention (Villarosa 2018; Roeder 2019). Intimately related is the maternal mortality rate, which has its own, even more staggering disparity. The white maternal mortality rate is currently 12.4 deaths per 100,000 white pregnant women compared to 40.0 deaths per 100,000 black pregnant women (CDC 2017). Easy alternative explanations such as class or education do not explain the data: black women still die at higher rates than white women even when they have similar educational backgrounds (Schoendorf, et al. 1992). ${ }^{17}$

A controversial explanation that has garnered considerable interest has been "weathering," a term that describes the effects of toxic stress caused by structural and institutional racism on a black woman's body, which increases the likelihood of high blood pressure, pre-eclampsia, and so on (Geronimus 1987; 1992; Geronimus, et al. 2006; Kramer and Hogue 2009). Of course, any regular symptom increase is further complicated and exacerbated by pregnancy, which only worsens the consequences of weathering. There are at least two good reasons to think the weathering hypothesis is true. Consider privileged or normally stressed

This also fits with findings that indicate that overuse and underuse can be idiosyncratic to certain diagnoses (Reid, Rabideau, and Sood 2016). Here, it seems that heart disease and heart attacks in black people is precisely the kind of convergence of symptoms, biases, and practices that add up to systemic overuse or underuse.

${ }^{17}$ A similar effect demonstrating racial bias over class-based issues was found in Williams and Wyatt (2015). 
women (e.g., white women in America) who have maternal mortality risks that resemble inverse bell curves - higher risk during teen years, then lower risk during years of prime health before rising again with age. Because there is more time for toxic stress to affect her body, the weathering hypothesis predicts that women who have weathered stress from racism will have a steadily increasing maternal mortality risk. This turns out to be true: it is actually less riskywith regard to the mother's life - to have a child as a teenager if one is a black woman than to have a child in one's 20s (Geronimus 1987). Second, allostatic load score analyses measure the amount of the toxic chemicals stress can leave behind in one's body. As weathering predicts, we find much higher levels of these chemicals in older black bodies (Geronimus, et al. 2006).

Weathering links the disparate numbers to black experience-specifically, the medical community's continuing ignorance of it. Not only do medical personnel hold false biological beliefs about black people, they also ignore the reports of black peoples' symptoms and experiences, consequently poisoning the chances of equitable and fair treatment. Black women are emblematic of this, as the evidence above shows (Geronimus 1987; 1992; Geronimus, et al. 2006; Kramer and Hogue 2009). ${ }^{18}$

Not only are black women more likely to experience the complications associated with weathering, but their experiences are discredited and their symptoms downplayed or ignored. Serena Williams's almost lethal experience after childbirth catalyzed some popular press of the well-documented disparities in the maternal mortality rate. After delivering her baby Olympia, Williams experienced several serious symptoms and told a nurse outside her room that she thought she was experiencing a blood clot, asking for blood thinner and tests. Her experience

\footnotetext{
${ }^{18}$ This extends to other spheres - for example, weathering and its effects might reduce political activism due to health reasons just when the population is likely to become increasingly interested in civic engagement, reducing the ability of weathered populations to gain political clout (Bound, et al. 2015).
} 
was at first dismissed — she must be confused from the pain killers. Williams continued to insist on testing, and they relented, allowing an ultrasound which showed nothing. Williams persisted and eventually secured a CT scan, which showed several blood clots (Roeder 2019; Villarosa 2018).

Medical education is no immunization to this dismissal. Shalon Irving was an epidemiologist at the CDC and worked specifically on racial and other health inequities. Despite her concern about her alarming postpartum symptoms, she was reassured that her symptoms were normal. Hours after her latest appointment, she collapsed and died (Roeder 2019; Villarosa 2018).

On top of the black maternal mortality rate, a tragedy all on its own, there are obvious downstream effects. The children must be raised without their mother, which means their family is missing additional income, community involvement, or the loving care of a mother (McLanahan and Sandefur 1994). These and other results might explain why being raised by a single parent is often correlated with worse health outcomes (Jennings and Sheldon 1985).

This is by no means all of the evidence for the medical community's ignorance of black women's lived experience. Take the fact that $26 \%$ of black women meet their birth attendants for the first time during childbirth compared to about $18 \%$ of white women. Black women are also less likely to have obstetrician-gynecologists as their birth attendants than white women (Declercq et al. 2013). ${ }^{19}$ All of this is just a tiny snapshot of what could be said about the lived experience of being black in America, but these two examples center the discussion around

\footnotetext{
${ }^{19}$ This denial or ignorance of experience is not limited to black women. Latina women, for example, were the least likely among women with chronic or gestational diabetes to be tested for high blood sugar in a post-partum visit (Declercq et al. 2013). They were also the most likely to be concerned that a medical error would occur around the time of birth and reported that they received poor treatment while hospitalized for birth at almost twice the rate of white women (although 2\% lower than black women). See Declercq et al. (2013).
} 
concerns of undertreatment, dismissal, and distrust that motivate the argument to abandon certain policies opposed to overtesting.

\section{MEDICAL OVERTESTING AND RACIAL DISTRUST}

Black people in America have had little reason to trust white people in positions of power over them. They have been captured, held, and forced to work against their will by and for white people. Later, almost any person of authority would abuse it in one way or another or else totally misunderstand the condition and needs of black people. This has been no different in the medical field. With such a large disconnect in understanding between black patients and white doctors further complicated by historical and present medical abuse, it is easy to see why distrust between black patients and white doctors would grow. We have evidence of this distrust between "free" black patients and white doctors from as far back as the early 1900s, when white doctors' complaints about treating black patients center on, among other things, black patients not coming to the doctor until their illness had already progressed significantly or not following the doctors' orders (Douglas 1926, 736-37; Hoberman 2012, 23; Airhihenbuwa, Ford, and Iwelunmor 2013). Today, medical professionals often feel that this distrust is unwarranted. "I nor anyone I know has done anything to earn your distrust," or "I didn't participate in the Tuskegee study," can often be sentiments expressed by doctors who are subjects of distrust to their patients. ${ }^{20}$ Nevertheless, individuals usually inherit their values from their community. A history of medical abuse and neglect has shaped the community of black Americans to be wary of the medical

\footnotetext{
${ }^{20}$ This sort of objection is undermined by certain accounts of systems, institutions, organizations, and communities. When one joins the Ku Klux Klan in a sufficiently serious way, one becomes culpable (in a certain way) as a member of that group for that group's past wrongdoing. This goes both ways. Joining a charity group in a sufficiently serious way earns you praise (in a certain way) as a member of that group due to that group's praiseworthy actions.
} 
profession (Gamble 1993). Although it is partially explainable this way, it is also misleading. Racism has become less conscious and more structural, but it is still ongoing (Gamble 1993; 1997; Hoberman 2012; Massey and Sampson 2009). So, for both historical considerations of abuse and present considerations of medical racism, it seems racial distrust has been well-earned by the medical community. ${ }^{21}$

I have no new policies that I will advocate here, but we can retain an existing practice that might prevent further medical neglect: overtesting. With this in mind, we can turn to principles of justice to see how these goods should be distributed.

A common proposal to combat overtesting is to discourage doctors from testing in cases in which the physician judges the test to be low in value or high in risk—-for an example in medical imaging, see (Hendee et al. 2010). The measures for this are not merely individual. The medical community must push to educate physicians on the tests that are the most wasteful, that are the lowest in value, and so on (Morgan et al. 2015; Morgan et al. 2016; Morgan et al. 2017; 2018). Furthermore, there should be structural change. One path suggested is eliminating measures that enforce overtesting, such as reducing the need for defensive medicine or eliminating financial kickbacks from ordering tests (Berwick and Hackbarth 2012; Mello, et al. 2010). This solution would only decrease the already-reduced care given to black Americans given the racial biases of physicians in the United States. Even if overtesting is harmful for nonblack Americans (or even for all patients), the reduction in appropriate testing that would result from implementing this policy is unacceptable. So, we should not bluntly discourage most

\footnotetext{
${ }^{21}$ Questions of redress are beyond the scope of this paper. For discussion, see Boxill (2016), Robinson (2000), Horowitz (2003), Coates (2014), and de Greiff (2006a; 2006b).
} 
overtesting of patients by physicians and therefore avoid increasing the high incidence of harmful medical error inflicted on certain racial minorities. ${ }^{22}$

There are myriad ways for overtesting to occur. Overtesting can be administering the same test more times than necessary, administering different tests but that are unlikely to discover anything of importance, and so on. In the discussion that follows, I want to focus on two particular kinds of overtesting. One is not a case of actual overtesting, but instead a case of perceived overtesting in which a doctor has formed a belief that further tests are not necessary or helpful (perhaps because of harmful stereotypes) when they in fact would be helpful or are necessary. In this case, perhaps a physician has some mistaken perception (due to bias or bad training) that causes them to evaluate the situation in such a way that they decrease the odds of a certain cause, taking it out of the range of needing to be tested for. ${ }^{23}$ Because of this mistaken evaluation, the physician then decides to withhold the test in order to reduce overtesting. ${ }^{24,25}$ The other case is actual overtesting, in which the helpfulness and necessity of the tests coincide with the doctor's belief that they would not be helpful or are not necessary. In this case, the physician evaluates the situation as not providing a medical basis for overtesting and is correct. If both cases turn out to be beneficial for oppressed minority groups, then we have reason to apply principles of distributive and restorative justice. Consider the following case:

Actual Overtesting: A black male is anxious about a few of his symptoms. The physician informs the patient that there is no reason to test the patient for any further underlying causes, but the physician administers the tests anyway after the patient persists. The

\footnotetext{
${ }^{22}$ At least black people in America, but possibly others. See note 8.

${ }^{23}$ It is important to note that almost all diagnostic evaluations are cases of inference to the best explanation and are therefore probabilistic rather than all-or-nothing (see Johnson forthcoming). So while it might be the case that a physician's biases lead them so far astray that there would be a complete lack of a medical basis for care, it is more likely that most situations involve cases in which the physician is forced to make a decision on narrower probabilities.

${ }^{24}$ There are other cases that can be constructed for using the same test fewer times than the actual situation requires due to decreased prior probability from the mistaken evaluation, and so on.

${ }^{25}$ I thank an anonymous reviewer for making me think more carefully about how to conceptualize overtesting, both perceived and actual.
} 
patient is relieved at the test results and returns home. The doctor has shown a willingness to listen to the patient even when there is no reason to think the tests will be helpful or necessary. ${ }^{26}$

There are two benefits from Actual Overtesting: (1) the patient's personal medical anxieties are relieved; and (2) there is some restoration of trust between the patient and the doctor. (1) is not usually considered to be sufficiently weighty to favor overtesting, since similar anxieties are present in white patients to the same or nearly the same degree, but few feel this justifies the practice of overtesting. Additionally, some test results will not return to the patient for significant periods of time, during which heightened medical anxiety or other negative mental states can be present. Thus, (1) is not sufficient for justifying overtesting on an individual basis.

Restoration of trust (2) has not been seriously considered by the medical community, perhaps because most do not believe it is in need of restoration or have dismissed it prematurely. There are a few reasons to think it would restore trust. One important reason is that it relieves anxiety not present or not present to the same degree for other patients: fear of withheld care. Because of the long history of withholding care to black Americans, the appearance of doing so is particularly harmful (Jones 1993; Gamble 1997; 1993; Krakauer and Truog 1997). A second reason is the trust shown by the physician first by listening and believing the patient. An additional consideration is that the transparency of the interaction helps in more than one way, both from a trust-building perspective and to better acquire informed-consent when the test is administered. Trust restoration is not present in the "usual" consideration of this problem because it is not present in cases involving overtesting and white patients. Despite this being a case of actual overtesting, it seems prima facie good for black communities. Perhaps this can be

\footnotetext{
${ }^{26}$ The point made here is very similar to the case study as presented in Krakauer and Truog (1997), although the issue is anxiety over harmless symptoms in Actual Overtesting and futile end-of-life care in their case.
} 
outweighed by other considerations (such as driving up costs), but this and other objections will be addressed later. Consider a different case:

Perceived Overtesting: A black female is anxious about a few of her symptoms. The physician has formed the belief that her symptoms are not the result of anything serious but, aware that she might be misperceiving the situation due to bias, agrees to extra tests regardless. The tests reveal that the patient has an underlying condition causing the symptoms. The doctor orders the proper treatment, and the condition is resolved without complication.

Like the previous case, the doctor has shown humility and awareness of racial bias in medical practice through her willingness to be open to something she missed regardless of the outcome of the tests. Furthermore, if something is found on the tests, the patient is greatly helped by the medical community rather than greatly harmed (as would happen if no test had been run). ${ }^{27}$ Therefore, cases of perceived overtesting that nevertheless get "overtested" can be extremely beneficial to people and communities of color. Furthermore, we have good reason to think there are a great number of perceived overtesting events given the arc of medical history in the United States. Consider again the cases of Serena Williams and Shalon Irving. In Perceived Overtesting, the result is a welcome one, but consider the resistance Williams and Irving received in response to their concerns, and the lethal result if they are ultimately denied further testing and care. There is also harder evidence, such as how black women were less likely than white women to receive testing for high blood sugar in a postpartum visit among women with chronic or gestational diabetes (Declercq et al. 2013). ${ }^{28}$

Perhaps more importantly is the harm prevented, however. Physicians who are encouraged to cut back on medical overtesting will be looking for occasions to cut back on what

\footnotetext{
27 This general example is meant to parallel the discussion of the black maternal mortality rate and the dismissal of black experiences in the medical field discussed previously.

${ }^{28}$ Latina women were the least likely of all groups to receive such testing.
} 
they perceive as unnecessary testing. Because both actual and perceived overtesting are phenomenologically indistinguishable to the physician at the time of deliberation, the physician will view both as candidate situations for withholding testing. Withholding testing in a case of perceived overtesting can be a great harm, medically and within the context of racial distrust regarding withholding care. Thus, the worry here is not merely losing the extra good that may come from overtesting, but also causing great harm by encouraging physicians to cut back on tests they perceive to be unnecessary or unlikely to help despite their necessity. In fact, Williams's experience is paradigmatic of the harm described in this paper. There is a push to reduce the use of the CT scan due to its financial cost and its high radiation level (Hendee et al. 2010). Medical personnel thereby become more reluctant to use the test. ${ }^{29}$ Couple this with unconscious racial biases such as over-reporting pain and dismissal of black experience and one can easily see how black women can end up untested and untreated in life-threatening circumstances.

There are also cases of testing that do not appear harmful if overlooked. Does this change the calculus of harm? Yes. But in every case, some harm occurs—if a test is justified based on the presentation of the symptoms, then it is overall better for the test to be performed than not. Even in cases of the least amount of physical harm, there appears to be a certain amount of dignitary harm that comes from not respecting the patient by undertesting them. But many tests are intended to help diagnose serious health problems, and so the risk of great harm is present in many cases. If the characterization or policy discouraging overtesting is not sufficiently nuanced, then cases of perceived overtesting will go without the necessary testing, causing serious harm. ${ }^{30}$ In fact, cases of Actual Overtesting can be unequivocally bad, and yet pursuing policies that seek

\footnotetext{
${ }^{29}$ See note 7.

${ }^{30}$ I discuss some of the advances I believe do not trigger these concerns in the final section.
} 
to reduce overtesting can still be outweighed by the risks of cutting back on necessary tests in cases of Perceived Overtesting.

We have just analyzed the two possibilities in a case of overtesting: actual overtesting and perceived overtesting. In one case, merely the act of testing to alleviate race-based anxiety helps to alleviate the overall phenomenon of racial distrust of the medical community, even if it is at some cost to the doctor or the healthcare system at large. In the other case, overtesting actually prevents harm from occurring to the patient, benefitting everyone involved and restoring trust between medical and black communities. ${ }^{31}$ Notably, it does not matter whether the overtesting is actual or perceived; racial trust is restored. Also noteworthy is the possibility of serious harm if racist medical mythology leads to higher incidence of perceived overtesting and the requisite tests are not administered. There are goods at stake in both cases, then, for people and communities of color. Overtesting that discovers disease, as well as restores trust, is a very great good and plausibly quite commonplace. ${ }^{32,33}$ As mentioned before, however, even if actual overtesting is certainly bad, the harms of perceived overtesting can still be great enough to outweigh the benefits of policies aimed at reducing overtesting.

\section{COST-BENEFIT ANALYSIS OF OVERTESTING}

\footnotetext{
${ }^{31}$ Cf., Krakauer and Truog (1997).

32 There are interesting issues here regarding the moral luck of such circumstances. For more on this topic, see Allhoff (2019).

${ }^{33}$ It might be objected that overtesting cannot mitigate undertreatment or undertesting because undertreatment and undertesting exist at the same time as the current climate of overtesting. But this does not consider that the climate of overtesting may well be mitigating some undertreatment and undertesting right now, and thus the removal of it would expand the reach of undertreatment and undertesting. Certainly allowing overtesting to continue will not solve all health inequities, but that is not my position. My position is that it may mitigate some of the harms of undertesting and the consequent undertreatment.
} 
Having argued that there are benefits to overtesting, I turn now to whether these benefits outweigh the costs of permitting medical overtesting to continue. First, consider the beneficial effects. We have seen that a confluence of factors including dismissal of black experience, false biological beliefs, and the push to reduce overtesting can result in what I have called perceived overtesting, in which a physician, due to evaluative mistakes or unconscious biases, believes testing would not be of sufficient help when in fact it would be medically appropriate to test. Failing to utilize tests in cases of perceived overtesting can result in great harm to the patient, and this harm becomes racialized if the patients are disproportionately black. Racialized harm is an especially bad kind of harm, one that should be avoided even at the cost of some net gains. ${ }^{34}$ Furthermore, current policies advocating for the reduction of overtesting will only discourage administration of tests in cases of perceived overtesting. Knowing this, utilizing tests in cases of perceived overtesting is a great good. We have also seen that, even in cases of actual-overtesting, there is good to be gained. Not only does the patient herself feel relieved, but this contributes to the much greater good of building trust between the medical community and communities of color.

Next, let's consider the costs. The first two are individual costs to overtesting. Considering people of color are often less well-off or impoverished (mostly due to previous racist treatment both interpersonally and structurally), it seems that medical bills could be far too expensive for most poor people of color. This would be a strong reason to not order tests that would appear to be unnecessary, since the bill could ruin their life just as well as the disease. Second, it is well-known that radiation has several negative effects: it is a carcinogen, can cause

\footnotetext{
${ }^{34}$ Not all or any net gains, merely some. It might be that there is some arrangement of testing such that harms go down slightly overall but the distribution of harms is racialized (e.g., perhaps black people in America experience fewer warranted tests than before). This strikes one as prima facie impermissible.
} 
tissue hardening, scarring, discoloration, and so on. Receiving too many radiation-based tests could harm a patient (Food and Drug Administration [FDA] 2017; Thomasian 2014). The computed tomography (CT) scan is a flagrant offender on this front. Because CT scans are quick and data-rich, they have become commonplace in emergency rooms, but its radiation dosage is the equivalent of 200 chest $\mathrm{x}$-rays (FDA 2017; Thomasian 2014). There is also an increase in costs of healthcare overall when there is a climate of overtesting. Because insurance companies foot most of the bills, they will pass that bill onto their clients, increasing premiums (or taxes, if healthcare is socialized). Finally, we must consider the cost to those who would not suffer racespecific harms if overtesting were bluntly discouraged but would still bear the burdens of overtesting. In order to weigh these considerations properly, let's consider each in turn.

When patients enter the emergency room, they can refuse almost any test or care. Patients are informed of the risks and costs of each test; otherwise, the physician would not have obtained informed consent. Therefore, we can hold the variable of the patient understanding the cost of overtesting constant. ${ }^{35}$ Hence, there are two possibilities that describe patients in cases of individual harm caused by overtesting. The first is a misestimate of the benefits of the test. In these cases, the patient just does not understand the chances of a successful test. ${ }^{36}$ Alternatively, the patient may accurately estimate the chances of a successful test and nevertheless thinks it is worth it, despite differing medical opinion (e.g., from opponents of unnecessary testing). The second case is easy to deal with: patients are not impermissibly harmed by overtesting because they would, given their values, prefer the test. In other words, there is not any harm present we

\footnotetext{
${ }^{35}$ Medical costs are, unfortunately, very opaque in the United States' healthcare system. This presents a problem of its own, but whose solution is (in theory) straightforward: the cost of healthcare in the U.S. should be revised to be much clearer; else we are missing out on true informed consent.

${ }^{36}$ A successful test is (roughly) a test in which there is a medical basis for the test, the test accurately detects whether the condition tested for is present, and the condition, if detected, can be well-treated.
} 
would not countenance in any other medical situation, especially given the commitment to the value of autonomy in medical environments. Pursuing aggressive, almost-certainly-futile lifesaving therapy is a harm to the patient, but it is a harm we allow the patient to pursue.

Overtesting is almost certainly less of a harm than aggressive-yet-futile therapy or dying after months unconscious on a ventilator at an advanced age.

The first case might seem harder to parse at first, but notice that, while overtesting might harm them in some way, the true solution is better communication about the benefits of the test. If they are misestimating just how unlikely it is, then the onus is on the physician (or medical personnel explaining the test's benefits) to communicate more clearly, lest we receive mere uninformed consent. ${ }^{37}$ This sort of analysis resolves concerns about both the cost of testing on one's health (radiation risks to one's health versus health benefits of the test results) and one's financial health (monetary cost versus health benefits of the test results). ${ }^{38}$ Still, there is a concern about how this communication should be fixed. If the physician has unconscious biases, how does the explanation of their mental state help the patient? Will it not have the same bias and therefore fail to communicate the risks and benefits?

While this is a serious concern, it is not unique to overtesting. Once again, this threatens informed consent in our medical systems in totality. Still, there is hope that simple measures aimed at improving informed consent might help — the physician might have to rethink their assessment of the patient's pain, or confront the fact that their evaluation of the patient is at odds

\footnotetext{
37 This would entail our medical industry is a sham; doctors are acting paternalistically while deceiving patients (and the public) into thinking we have a say in our treatment. I take this route to be a dead-end.

${ }^{38}$ This has a further problem: it seems that racial bias would also work against problems of informed consent. This might be alleviated by nuanced solutions such as feedback-focused reforms that I mention at the end of the paper. For examples, see Hannan et al. (2018), Hannan et al. (2014), and Hannan et al. (2010).
} 
with the patients' testimony, or the odd explanation may indicate to the patient that there is something fishy going on. ${ }^{39,40}$

Beyond the interpersonal case, there are issues that do not concern the individual patient weighing the costs and benefits. The third part of the concern about overtesting involved the financial situation broadly construed. Although the analysis above should deal with both issues, it is worth pointing out that there are alternatives to depriving patients of medical care when they cannot afford it. Programs such as Public Aid, Medicare, Medicaid, and so on help the poor afford medical costs. Should these prove insufficient, it does not seem as if the climate of overtesting is the obvious change to make. One alternative is to make the case for different healthcare systems. Drawing on the analysis above, one can argue that the poor should not suffer consequences of perceived overtesting simply because they are poor, especially when their poverty might be due to racist institutions or history. ${ }^{41}$ The analysis provided here strongly supports crucial premises in traditional arguments for universal access to healthcare. ${ }^{42,43}$

\footnotetext{
${ }^{39}$ There are also proposals and research done on how to improve communication through cultural competency among other things, which will in turn increase the likelihood of securing informed consent. For more discussion and analysis, see Betsch et al. (2016).

${ }^{40}$ Thanks to an anonymous reviewer and Sandra Borden for pushing me on this point.

${ }^{41}$ Systems such as single-payer still care about efficiency; still, it would solve the individual financial case, which is what I focus on here. Costs to the system at large will be addressed shortly.

${ }^{42}$ This is particularly true for Rawlsian arguments for universal healthcare access (Rawls 1988). For example, consider premise three in Daniels (2017):

"Various socially controllable factors contribute to maintaining normal functioning in a population and distributing health fairly in it, including traditional public health and medical interventions, as well as the distribution of such social determinants of health as income and wealth, education, and control over life and work."

The social determinants of health mentioned would include racial aspects such as past injustices and physicians holding false beliefs due to cultural stereotyping and institutional racism (Hoberman 2012). Thus, the analysis given here would strongly support a crucial premise in Daniels's argument.

Deborah Stone takes this in a slightly different direction, arguing that something like market ideology guarantees racial inequality. For more, see Stone (2005).

${ }^{43}$ Here I assume something like Rawls's Difference Principle (Rawls 1988). Political theory and philosophy are beyond the scope of this paper, and those disagreeing with the Difference Principle or something like it may simply disagree with me here.
} 
The final two considerations run parallel. There are those — such as wealthy, white menwho would not be harmed by a blunt-solution to overtesting but would be harmed by the continuance of overtesting. These burdens might include personal financial problems, personal health risks, and overall cost to the system. There are two ways to frame and answer the objection. The first way the objection might be presented would be an individual sense. The answer to this form resides in the above arguments involving informed consent.

The second has to do with the balance of harms and benefits as spread across all affected, making it essentially a problem of distributive justice. White, wealthy men are currently harmed by medical overtesting, but black women would be harmed if certain solutions to overtesting are implemented. In order to avoid rehashing debates over the nature of distributive justice, consider how one influential conception balances the harms. Following Rawls:

Social and economic inequalities are to be arranged so that they are both: (a) to the greatest benefit of the least advantaged, consistent with the just savings principle, and (b) attached to offices and positions open to all under conditions of fair equality of opportunity. $(1988,266)$

Notice that the overall benefits here do not favor the least advantaged. The least advantaged here (racial minorities) would instead be harmed by blunt solutions to overtesting. Thus, it would be impermissible under Rawlsian distributive justice principles to implement solutions to overtesting that have this deleterious effect. ${ }^{44,45}$

\footnotetext{
${ }^{44}$ This leaves open the possibility of a system that only over-tests minority groups as a solution. I take this to be an ineffective solution for two reasons: (1) it seems impossible to implement the solution without having to address the very problems causing the problem in the first place and (2) the shift to race-conscious solutions is more likely to fall in favor of the solutions studied by Hannan et al. $(2018 ; 2010)$ mentioned at the end of the paper with much less resistance and greater effect.

${ }^{45}$ A forteriori, if one is convinced of some sort of reparations framework, it is entirely possible that the utilitarian calculus weighs against overtesting and yet we still ought to keep it due to the origin of the problem (racism) and the parties being harmed and benefitting from the system.
} 
Another popular conception of distributive justice is utilitarian. Here, the question faced is just the cost to the system at large if overtesting is maintained. Although the current healthcare system is extremely expensive, it is not clear that overtesting is even close to being one of the most significant factors. In a commissioned report, the University of Virginia Miller Center found nine of the most significant drivers of healthcare costs in the United States. Although overuse of CT scans was mentioned (about double the average of other developed countries), it is only mentioned briefly as a part of a much larger phenomenon of Americans assuming expensive treatments are the same as higher-quality treatments (Thomasian 2014). Berwick and Hackbarth identify six ways to reduce the huge financial cost of medical overuse. Medical testing is mentioned just once: as an example of pricing failures (2012). ${ }^{46}$ But, even if overtesting turned out to be a significant driver of healthcare costs, there are many other costs that could be reformed before overtesting that would not correspondingly cause further harm to communities of color. ${ }^{47}$

There might be a final concern of achievability. Perhaps the other drivers of healthcare costs are simply unachievable relative to lesser costs like overtesting. ${ }^{48}$ But this does not bear out in the reports of the authors writing about the drivers of healthcare costs. First, the primary drivers of healthcare costs are so expensive that "achieving even a fraction of that amount in the short run" could result in serious savings, stability, and prevent harm to patients (Berwick and Hackbarth 2012, 1515). There are also state-based alternatives laid out in other reports of a similar kind, with specific steps and recommendations for cutting these drivers of costs (Thomasian 2014). As noted before, these need only be mildly successful to compare very

\footnotetext{
${ }^{46}$ U.S. American imaging is priced to be several times more than identical procedures in other countries (International Federation of Health Plans 2010).

${ }^{47}$ For examples, see Berwick and Hackbarth (2012).

${ }^{48}$ Thanks to T.J. Broy for this objection.
} 
favorably with reform efforts in overtesting. If we are going to focus our solutions due to limited resources, it makes sense to cut out issues that are uncontroversially bad before turning to other, more controversial issues.

\section{SOME HELPFUL ADVANCES}

The case against unnecessarily testing patients for conditions is intuitive and widely accepted. It is also wrong. Once we keep the history of medical racism in mind, we see that our climate of overtesting is surprisingly beneficial to communities of color in two ways: (1) it prevents commonplace cases of perceived overtesting from greatly harming the patient, and (2) even in cases where testing is actually unwarranted, it restores trust between the medical community and black people in America as well as avoiding harm caused by perceptions of withholding treatment. Objections to overtesting usually overlook important explanatory features of the medical industry. The nature of overtesting harms and benefits are misconstrued or undertheorized. Similarly, the compromised epistemic position of physicians when determining whether a certain test is necessary is often missed, both in a contemporary and historical context. Finally, there are several other uncontroversially bad problems that could be solved before addressing problems such as overtesting, which has noteworthy benefits for communities of color. Therefore, the distributions of benefits and harms give us a powerful reason to retain our current climate of overtesting.

My argument does not preclude solutions to overtesting; it merely demands that they be nuanced such that the race-specific harms associated with blunt discouragement are not present. There is an extensive literature on the risks and benefits of tailoring policies with race as a variable (King 1992; Osborne and Feit 1992; Comstock, Castillo, and Lindsay 2004; Kaplan and 
Bennett 2003; King 2007; Bonilla-Silva 2017). It distinguishes between "race-neutral" or "colorblind" policies that do not use race as a variable and "race-conscious" policies, which do. Patricia King argues that race-conscious policies risk reifying racial stereotypes but are often the only policies that can properly address racial inequalities $(1992 ; 2007)$. She proposes some criteria for acceptable race-conscious policies: they should be short-term in nature and no broader in scope than their use demands (2007). Moving forward, likely some mix of raceconscious and race-neutral solutions should be carefully considered. Some piecemeal raceneutral solutions that appear to sufficiently address my concerns are already popping up, such as specialty-specific waste analyses documenting the most-used and least-useful tests. ${ }^{49}$

More race-conscious reforms might look like feedback-focused attempts to close racial gaps in testing and diagnosis. Solutions as simple as recording the race, ethnicity, and gender of each patient of a provider, running analyses to see if there are gaps along those lines, and then providing the medical professional with their results appear to work well in the studies led by Hannan (Hannan et al. 2018, Hannan et al. 2014, Hannan et al. 2010). This sort of feedback could be mandated, and even financial penalties assessed if disparities continue. This would parallel the significant success of a similar policy of mandated measurement of hospital and physician quality of care by the Centers for Medicare and Medicaid Services (U.S. Department of Health and Human Services 2018). ${ }^{50}$ Another promising alternative are the community-based participatory research models that have shown some success at reducing racial and ethnic health disparities (Stone, et al. 2014). These and other nuanced solutions would work toward ending overtesting without the race-specific harms other common solutions to overtesting threaten.

\footnotetext{
${ }^{49}$ Some of the waste noted in the updates by Daniel Morgan and colleagues might also qualify.

50 Thanks to an anonymous reviewer who pointed me to this sort of solution.
} 
Overtesting has been thought of as uncontroversially bad, but I have argued the downsides of the current sentiment to reduce overtesting has unacceptable consequences due to the phenomenon of perceived overtesting. Furthermore, it may have significant and surprising benefits, such as restoring trust between the medical community and racial minorities. Therefore, even assuming overtesting is a significant driver of healthcare costs, we should focus our attention elsewhere before advocating for the elimination of overtesting from the healthcare system. This is especially true if we have no sufficiently nuanced alternative proposal to restore trust between communities of color and communities of medicine and prevent the medical error that regularly occurs due to racial biases in the medical field. Still, there are solutions that avoid the worries presented here, usually by adapting race-neutral proposals into race-conscious proposals, or by building policies by beginning with the fact of racial disparities. Regardless, the discussion around overtesting must change.

\section{ACKNOWLEDGEMENTS}

I would like to thank Fritz Allhoff, Sandra Borden, and Thomas Golemon for their comments, suggestions, and support. I would also like to thank three anonymous reviewers and the editors at the KIEJ for their helpful and insightful comments.

\section{REFERENCES}

Airhihenbuwa, Collins, and Leandris Liburd. 2006. "Eliminating Health Disparities in the African American Population: The Interface of Culture, Gender, and Power." Health Education and Behavior 33 (4): 488-501. 
Airhihenbuwa, Collins, Chandra Ford, and Juliet Iwelnmor. 2013. "Why Culture Matters in Health Interventions: Lessons From HIV/AIDS Stigma and NCDs.” Health Education and Behavior 41 (1): 78-84.

Allhoff, Fritz. 2019. "Medical Error and Moral Luck," Kennedy Institute of Ethics Journal 29 (3): [PAGES TK].

Allhoff, Fritz, and Sandra Borden eds. Forthcoming. Ethics and Medical Error. New York: Routledge. Alspector-Kelly, Marc. 2019. Against Knowledge Closure. Cambridge: Cambridge University Press.

Anderson, Karen, Carmen Green, and Richard Payne. 2009. "Racial and Ethnic Disparities in Pain: Causes and Consequences of Unequal Care," Journal of Pain 10 (12): 1187-1204. Berwick, Donald, and Andrew Hackbarth. 2012. "Eliminating Waste in US Health Care." Journal of the American Medical Association 307: 1513-16.

Betsch, Cornelia, Robert Böhm, Collins O. Airhihenbuwa, et al. 2016. "Improving Medical Decision Making and Health Promotion through Culture-Sensitive Health Communication: An Agenda for Science and Practice.” Medical Decision Making 36 (7): 795-97.

Bishop, Tara, Alex Federman, and Salomeh Keyhani. 2010. "Physicians' Views on Defensive Medicine: A National Survey.” Archives of Internal Medicine 170: 1081-83.

Boland, Benoit, Peter Wollan, and Marc Silverstein. 1996. "Yield of Laboratory Tests for CaseFinding in the Ambulatory General Medical Examination.” American Journal of Medicine 101: 142-52.

Bonilla-Silva, Eduardo. 2017. Racism without Racists: Colorblind Racism and the Persistence of Racial Inequality in the United States, $5^{\text {th }}$ edition. New York: Rowman \& Littlefield Publishers. 
Bound, John, Arline Geronimus, Javier Rodriguez, and Timothy Waidmann. 2015. "Measuring Recent Apparent Declines in Longevity: The Role of Increasing Educational Attainment." Health Affairs 34 (12): 2167-73.

Boxill, Bernard. 2016. "Black Reparations.” The Stanford Encyclopedia of Philosophy (Summer 2016 edition), edited by Edward N. Zalta. https://plato.stanford.edu/archives/sum2016/entries/black-reparations/

Byrd, Michael, and Linda Clayton. 2000. An American Health Dilemma: A Medical History of African Americans and the Problem of Race. New York: Routledge.

—. 2001. "Race, Medicine, and Health-care in the United States: A Historical Survey." Journal of the National Medical Association 93 (3): 11-34.

Carter, Stacy, Wendy Rogers, I. Heath, Chris Degeling, Jenny Doust, and Amy Barratt. 2015. “The Challenge of Overdiagnosis Begins with Its Definition.” BMJ 350: 1-5.

Centers for Disease Control. 2017. "Reproductive Health." Centers for Disease Control and Prevention. https://www.cdc.gov/reproductivehealth/index.html

Cintron, Alexie, and Sean Morrison. 2006. "Pain and Ethnicity in the United States: A Systematic Review.” Journal Palliative Medicine 9 (6): 1454-73.

Coates, Ta-Nehisi. 2014. “The Case for Reparations.” June. The Atlantic. https://www.theatlantic.com/magazine/archive/2014/06/the-case-for-reparations/361631/. Comstock, Dawn, Edward Castillo, and Suzanne Lindsay. 2004. "Four-Year Review of the Use of Race and Ethnicity in Epidemiologic and Public Health Research.” American Journal of Epidemiology 159: 611-19. 
Daniels, Norman. 2017. "Justice and Access to Health Care." The Stanford Encyclopedia of Philosophy (Winter 2017 edition), edited by Edward N. Zalta. https://plato.stanford.edu/archives/win2017/entries/justice-healthcareaccess/

Declercq, Eugene, Carol Sakala, Maureen Corry, Sandra Applebaum, and Peter Risher. 2013. Listening to Mothers III: New Mothers Speak Out. New York: Childbirth Connection. http://transform.childbirthconnection.org/wp-content/uploads/2013/06/LTM-

\section{Pregnancy-and-Birth.pdf}

Doll, Kemi, Cyndy Snyder, and Chandra Ford. 2018. "Endometrial Cancer Disparities: A RaceConscious Critique of the Literature.” American Journal of Obstetrics \& Gynecology 218 (5): 474-82.

Douglas, S. 1926. "Difficulties and Superstitions Encountered in Practice among the Negroes." Southern Medical Journal 19 (10).

Drake, St. Clair. 1987. Black Folk Here and There: An Essay in History and Anthropology, volume 1. Center for Afro-American Studies, University of California. 1990. Black Folk Here and There: An Essay in History and Anthropology, volume 2. Center for Afro-American Studies, University of California.

DuBois, William. 1899. The Philadelphia Negro. University of Pennsylvania Press. Food and Drug Administration. 2017. "What are the Radiation Risks from CT?" U.S. Department of Health and Human Services. https://www.fda.gov/radiation-emittingproducts/medical-x-ray-imaging/what-are-radiation-risks-ct

Freeman, Harold, and Richard Payne. 2000. "Racial Injustice in Health-care.” New England Journal of Medicine 342 (14): 1045-47. 
Gamble, Vanessa. 1993. “A Legacy of Distrust: African Americans and Medical Research.” American Journal of Preventative Medicine 9: 35-38. 1997. "Under the Shadow of Tuskegee: African Americans and Health Care." American Journal of Public Health 87: 1773-78.

Gee, Gilbert, and Chandra Ford. 2011. "Structural Racism and Health Inequities: Old Issues, New Directions.” Du Bois Review Social Science Research on Race 8 (1): 115-32. Geronimus, Arline. 1987. “On Teenage Childbearing and Neonatal Mortality in the United States." Population and Development Review 13 (2): 245. 1992. "The Weathering Hypothesis and the Health of African-American Women and Infants: Evidence and Speculations.” Ethnicity and Disease 2 (3): 207-21.

Geronimus, Arline, Margaret Hicken, Danya Keene, and John Bound. 2006. “'Weathering” and Age Patterns of Allostatic Load Scores Among Blacks and Whites in the United States." American Journal of Public Health 96 (5): 826-33.

Greenberg, Jerome, and Jonas Green. 2014. "Overtesting: Why More Is Not Better.” The American Journal of Medicine 127 (5): 362-63.

de Greiff, Pablo. 2006a. The Handbook of Reparations. Oxford: Oxford University Press. 2006b. "Justice and Reparations." In The Handbook of Reparations, edited by P. de Greiff, 451-77. Oxford: Oxford University Press.

Hannan, Edward, Zaza Samadashvili, Kimberly Cozzens, et al. 2018. “Appropriate Use Criteria for Percutaneous Cornoary Interventions: Impact on Appropriateness Ratings." Journal of American College of Cardiology: Cardiovascular Interventions 11: 473-78.

Hannan, Edward, Zaza Samadashvili, Kimberly Cozzens, et al. 2014. "Assessment of the New Appropriate Use Criteria for Diagnostic Catheterization in the Detection of Cornoary 
Artery Disease Following Noninvasive Stress Testing.” International Journal of Cardiology 170 (3): 371-75.

Hannan, Edward, Michael Racz, Jeffrey Gold, et al. 2010. "Adherence of Catheterization Laboratory Cardiologists to American College of Cardiology/American Heart Association Guidelines for Percutaneous Coronary Interventions and Coronary Artery Bypass Graft Surgery: What Happens in Actual Practice?” Circulation 121: 267-75.

Hendee, William, Gary Becker, James Borgstede, et al. 2010. “Addressing Overutilization in Medical Imaging.” Radiology 257 (1): 240-45.

Hoberman, John. 1997. Darwin's Athletes: How Sport Has Damaged Black America and Preserved the Myth of Race. New York: Houghton Mifflin Company.

- 2012. Black \& Blue. Oakland: University of California Press.

Hoffman, Kelly, Sophie Trawalter, Jordan Axt, and Norman Oliver. 2016. "Racial Bias in Pain Assessment and Treatment Recommendations, and False Beliefs about Biological Differences between Blacks and Whites." Proceedings of the National Academy of Sciences of the United States of America 113 (16): 4296-301.

Horowitz, David. 2003. Uncivil Wars: The Controversy over Reparations for Slavery. San Francisco: Encounter Books.

Institute of Medicine. 2001. "Crossing the Quality Chasm: A New Health System for the $21^{\text {st }}$ Century." March. Washington, DC: National Academies Press. http://www.nationalacademies.org/hmd/ /media/Files/Report\%20Files/2001/Crossingthe-Quality-Chasm/Quality\%20Chasm\%202001\%20\%20report\%20brief.pdf 
International Federation of Health Plans. 2010. "Comparative Price Report: Medical and Hospital Fees by Country.” https://studylib.net/doc/14681602/international-federationof-health-plans-2010-comparative

Jha, Ashish, Elliott Fisher, Zhonghe Li, John Orav, and Arnold Epstein. 2005. "Racial Trends in the Use of Major Procedures among the Elderly." The New England Journal of Medicine 353: 683-91.

Jennings, A., and M. Sheldon. 1985. "Review of the Health of Children in One-Parent Families." The Journal of the Royal College of General Practitioners 35 (279): 478-83.

Johnson, David Kyle. Forthcoming. "Inference to the Best Explanation and Avoiding Diagnostic Error." In Ethics and Error in Medicine, edited by Fritz Allhoff and Sandra Borden. New York: Routledge University Press.

Jones, James. 1993. Bad Blood. New York: Free Press.

Kaplan, Judith, and Trude Bennett. 2003. "Use of Race and Ethnicity in Biomedical Publication." Journal of the American Medical Association 289 (20): 2709-16.

King, Patricia. 1992. “The Dangers of Difference.” The Hastings Center Report 22 (6): 35-38.

2007. "Race, Equity, Health Policy, and the African American." In African American Bioethics: Culture, Race and Identity, edited by L. Prograis and E. Pellegrino, 67-92. Washington DC: Georgetown University Press.

Kohn, Linda, Janet Corrigan, and Molla Donaldson. 2000. To Err Is Human: Building a Safer Health System. Washington, DC: National Academies Press.

Krakauer, Eric, and Robert Truog. 1997. "Mistrust, Racism, and End-of-Life Treatment.” The Hastings Center Report 27 (3): 23-25. 
Kramer, Michael, and Carol Hogue. 2009. "What Causes Racial Disparities in Very Preterm Birth? A Biosocial Perspective.” Epidemiologic Reviews 31 (1): 84-98.

Larson, David, Lara Johnson, Beverly Schnell, Shelia Salisbury, and Howard Forman. 2011. "National Trends in CT Use in the Emergency Department: 1995-2007." Radiology 258 (1): 164-73.

Lewis, Bernard. 1990. Race and Slavery in the Middle East: An Historical Enquiry. Oxford: Oxford University Press.

Makary, Martin, and Michael Daniel. 2016. "Medical Error-The Third Leading Cause of Death in the US.” BMJ 353: i2139.

Massey, Douglas, and Robert Sampson. 2009. "Introduction: Moynihan Redux: Legacies.” In The Moynihan Report Revisited: Lessons and Reflections after Four Decades. The Annals of The American Academy of Political and Social Science 621: 17.

McBride, David. 2018. Caring for Equality: A History of African American Health and Healthcare. New York: Rowman \& Littlefield Publishers.

McLanahan, Sara, and Gary Sandefur. 1994. Growing Up with a Single Parent: What Hurts, What Helps. Cambridge: Harvard University Press.

Mello, Michelle, Amitabh Chandra, Atul Gawande, and David Studdert. 2010. "National Costs of the Medical Liability System." Health Affairs 29 (9): 156-77.

Montagu, Ashley. 1963. Race, Science and Humanity. New York: Van Nostrand Reinhold Company.

Morgan, Daniel, Shannon Brownlee, Aaron Leppin, et al. 2015. "Setting a Research Agenda for Medical Overuse." BMJ 351: h4534. 
Morgan, Daniel, Sanket Dhruva, Scott Wright, and Deborah Korenstein. 2016. "2016 Update on Medical Overuse: A Systematic Review.” JAMA Internal Medicine 176 (11): 1687-92.

Morgan, Daniel, Sanket Dhruva, Eric Coon, Scott Wright, and Deborah Korenstein. 2017. “2017 Update on Medical Overuse: A Systematic Review." JAMA Internal Medicine 178 (1): $110-15$.

_.2018. "2018 Update on Medical Overuse.” Journal of the American Medical Association Internal Medicine 179 (2): 240-46.

Morning, Ann. 2011. The Nature of Race: How Scientists Think and Teach About Human Difference. Oakland: University of California Press.

Niles, Lauren, Monika Goyal, Gia Badolato, James Chamberlain, and Joanna Cohen. 2017. "US Emergency Department Trends in Imaging for Pediatric Nontraumatic Abdominal Pain.” Pediatrics 140 (4): 1-6.

Nuland, Sherwin. 2011. Doctors: The Biography of Medicine. New York: Vintage Books.

Osborne, Newton, and Marvin Feit. 1992. “The Use of Race in Medical Research.” Journal of the American Medical Association 267 (2): 275-79.

Rawls, John. 1988. A Theory of Justice, revised edition Cambridge MA: Belknap Press.

Reid, Rachel, Brendan Rabideau, and Neeraj Sood. 2016. "Low-Value Health Care Services in a Commercially Insured Population.” JAMA Internal Medicine 176 (10): 1567-71.

Robinson, Randall. 2000. The Debt: What America Owes to Blacks. New York: Penguin. Roeder, Amy. 2019. “America Is Failing Its Black Mothers.” Harvard Public Health. Winter issue. https://www.hsph.harvard.edu/magazine/magazine_article/america-is-failing-itsblack-mothers/ 
Rosenberg, Charles. 1987. The Care of Strangers: The Rise of America's Hospital System. New York: Basic Books.

Schoendorf, Kenneth, Carol Hogue, Joel Kleinman, and Diane Rowley. 1992. "Mortality Among Infants of Black as Compared with White College-Educated Parents.” The New England Journal of Medicine 326: 1522-26.

Schulman, Kevin, Jesse Berlin, William Harless, et al.1999. "The Effect of Race and Sex on Physicians' Recommendations for Cardiac Catheterization." The New England Journal of Medicine 340: 618-36.

Shapiro, Martin F., and Sheldon Greenfield. 1987. "The Complete Blood Count and Leukocyte Differential Count: An Approach to Their Rational Application." Annals of Internal Medicine 106: 65-74.

Smedley, Brian, Alan Nelson, and Adrienne Stith. 2003. Unequal Treatment: Confronting Racial and Ethnic Disparities in Health-care. Washingto, DC: National Academies Press.

Smith, Richard. 1991. "Where is the Wisdom...?” BMJ 303: 798-99.

Staton, Lisa, Mukta Panda, Ian Chen, et al. 2007. "When Race Matters: Disagreement in Pain Perception between Patients and Their Physicians in Primary Care." Journal of the National Medical Association 99 (5): 532-38.

Stone, Deborah. 2005. "How Market Ideology Guarantees Racial Inequality.” In Healthy, Wealthy, and Fair: Health Care and the Good Society, edited by J. Morone and Lawrence Jacobs, 65-90. Oxford: Oxford University Press.

Stone, Lisa, Nina Wallerstein, Analilia Garcia, and Meredith Winkler. 2014. "The Promise of Community-Based Participatory Research for Health Equity: A Conceptual Model for Bridging Evidence with Policy." American Journal of Public Health 104 (9): 1615-23. 
Thomasian, John. 2014. Cracking the Code on Health-care Costs. Charlottesville: The University of Virginia Miller Center.

U.S. Department of Health and Human Services. 2018. National Impact Assessment of the Centers for Medicare \& Medicaid Services (CMS) Quality Measures Report. Centers for Medicare \& Medicaid Services. https://www.cms.gov/Medicare/Quality-Initiatives-PatientAssessment-Instruments/QualityMeasures/Downloads/2018-Impact-Assessment-Report.pdf.

Williams, David, and Chiquita Collins. 2001. "Racial Residential Segregation: A Fundamental Cause of Racial Disparities in Health." Public Health Reports 116 (5): 404-16.

Williams, Melissa, and Jennifer Eberhardt. 2008 "Biological Conceptions of Race and the Motivation to Cross Racial Boundaries." Journal of Personality and Social Psychology 94 (6): 1033-47.

Williams, David, and Ronald Wyatt. 2015. "Racial Bias in Health Care and Health: Challenges and Opportunities." JAMA 314 (6): 555-56.

Villarosa, Linda. 2018. "Why America's Black Mothers and Babies Are in a Life-or-Death Crisis." April 11. The New York Times. https://www.nytimes.com/2018/04/11/magazine/black-mothers-babies-death-maternalmortality.html 